\title{
Charge Carrier Density Tuning of Graphene by Water Gating
}

\author{
Received November 18, 2019; accepted December 5, 2019
}

\author{
Young-Jun Yu* \\ Department of Physics, Chungnam National University, Daejeon 34134, Republic of Korea
}

*Corresponding author E-mail: yjyu@cnu.ac.kr

\begin{abstract}
In this work, the conditions of water-gated carrier density accumulation on graphene were investigated. In particular, either negative or positive electric potential in deionized water could be observed, leading to an increase or decrease in the hole charge carrier density, respectively. Furthermore, it was determined that the critical positive electric potential for water gating of graphene is required to return the accumulated carrier density back to its initial state. Taken together, these results provide valuable insight into the relationship between carrier accumulation and the deionized water gating method.
\end{abstract}

Keywords: Graphene, Carrier density, Water gating

\section{Introduction}

Graphene has been favored for atomically thin electrodes for nano-scale devices due to its high electrical conductivity [1-3]. Since the high charge carrier doping condition of graphene is one of the critical requirements for high conductivity electrodes, the accumulation of carrier density on graphene has been extensively studied. The use of electrolytes to potentially produce highly doped graphene by various methods has also been investigated for applications in several fields [4-13]. However, when a critical electric potential is applied to graphene via electrolytes such as ionic liquid or gel [7-9], undesired $\mathrm{sp}^{3}$ bonds were observed to form on the graphene [4-13] Thus, in order to maintain distinct $\mathrm{sp}^{2}$ electric potential structures on graphene during the application of an electric gate voltage, a stable electrolyte is required. Water is a promising electrolyte for this use, and water-gated field effect transistors have previously been reported [5,12]. However, more detailed information regarding the carrier density variation of graphene with water-gating is required.

In this work, the behavior of carrier density accumulation on graphene is investigated. In particular, the ability to tune the carrier density when employing deionized (DI) water gating with electric potential is explored. Finally, detailed information regarding the effect of accumulating charge carriers on graphene when either negative or positive electric potential is supplied through DI-water is presented.

\section{Experimental details}

In order to identify graphene conductance, graphene was prepared on a 280 -nm-thick silicon dioxide $\left(\mathrm{SiO}_{2}\right)$ /highly doped silicon (Si) substrate by the mechanical exfoliation method. Subsequently, titanium (Ti) electrodes were placed in contact with graphene by a conventional electron-beam lithography process [Figs. 1(a) and 1(b)]
$[8,9,13]$. Owing to the natural formation of a thin oxide layer on $\mathrm{Ti}$ when exposed to air, this oxide was employed as a barrier for blocking the interaction between the water-gate and Ti electrodes. As shown in Fig. 1(a), the resistance variation of graphene was inspected by twoterminal measurement during the application of either back-gate voltage $\left(\mathrm{V}_{\mathrm{BG}}\right)$ or water-gated voltage $\left(\mathrm{V}_{\mathrm{WG}}\right)$ through a $\mathrm{SiO}_{2} / \mathrm{Si}$ substrate or DI-water (resistivity $=8 \sim 10 \mathrm{M} \Omega$ )/platinum $(\mathrm{Pt}$ ) bar, respectively.

Figures 2(a) and 2(b) show the resistance of graphene as a function of $\mathrm{V}_{\mathrm{BG}}$ and $\mathrm{V}_{\mathrm{WG}}$, respectively. As shown in these figures, the initially accumulated carrier density in graphene was $n=\left(\mathrm{C}_{\mathrm{BG}} / e\right)$. $\mathrm{V}_{\mathrm{CNP}-\mathrm{BG}} \approx 5 \times 10^{11} \mathrm{~cm}^{-2}$, where $\mathrm{C}_{\mathrm{BG}}=12 \mathrm{nF} / \mathrm{cm}^{2}$ is the capacitance of the 280-nm-thick $\mathrm{SiO}_{2}$ substrate, $e$ is the charge of an electron, and $\mathrm{V}_{\mathrm{CNP}-\mathrm{BG}}=8.35 \mathrm{~V}$ is the charge neutral point. When DI-water gating is used instead of the $\mathrm{SiO}_{2}$ substrate for the same graphene, the charge neutral point $\mathrm{V}_{\mathrm{CNP}-\mathrm{WG}}=0.15 \mathrm{~V}$. The capacitance of DI-water $\left(\mathrm{C}_{\mathrm{WG}}\right)$ was calculated to be $\mathrm{C}_{\mathrm{WG}}=668 \mathrm{nF} / \mathrm{cm}^{2}$, because the initial accumulation of carrier density under applied $\mathrm{V}_{\mathrm{BG}}$ corresponded with the (a)

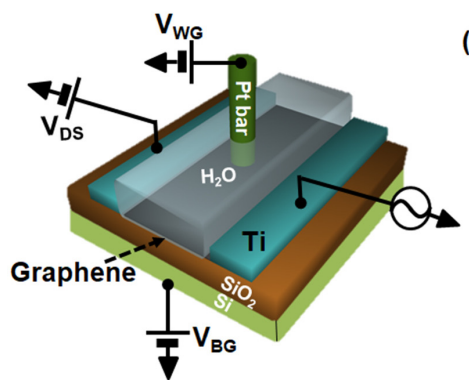

(b)

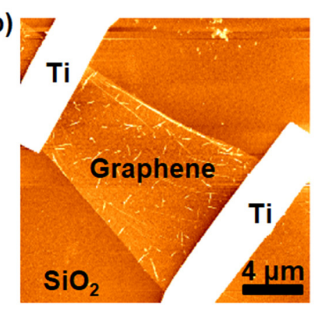

Figure 1. (Color online) (a) Schematic diagram of water gating by a platinum bar for graphene FET with Ti electrodes. (b) Topography image of graphene FET in contact with $\mathrm{Ti}$ electrodes on an $\mathrm{SiO}_{2}$ / $\mathrm{Si}$ substrate. Here it was utilized highly doped silicon substrate for applying back-gate voltage, $V_{B G}$. 

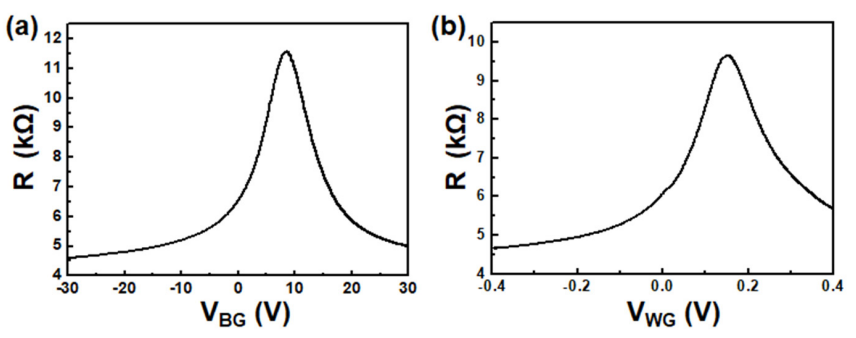

Figure 2. Resistance variation of graphene as a function of (a) back-gate voltage, $\mathrm{V}_{\mathrm{BG}}$ and (b) water-gate voltage, $\mathrm{V}_{\mathrm{WG}}$.

accumulated density under applied $\mathrm{V}_{\mathrm{WG}}$ as follows,

$$
n=\left(\mathrm{C}_{\mathrm{BG}} / e\right) \cdot \mathrm{V}_{\mathrm{CNP}-\mathrm{BG}}=\left(\mathrm{C}_{\mathrm{WG}} / e\right) \cdot \mathrm{V}_{\mathrm{CNP}-\mathrm{WG}}[10-12,14]
$$

\section{Results and discussion}

Figure 3 shows the resistance of graphene as a function of time for different values of applied $V_{\mathrm{WG}}$. When the (1) $\mathrm{V}_{\mathrm{WG}}=-0.6 \mathrm{~V}$ was applied to graphene, a decreased resistance of approximately $4.4 \mathrm{k} \Omega$ was observed. Subsequently, the resistance of graphene was measured as $5.4 \mathrm{k} \Omega$ for (2) $\mathrm{V}_{\mathrm{WG}}=0.6 \mathrm{~V}$ and as $4.3 \mathrm{k} \Omega$ for (7) $\mathrm{V}_{\mathrm{WG}}=2.0 \mathrm{~V}$. Furthermore, $\mathrm{V}_{\mathrm{WG}}=(1)-0.6 \mathrm{~V}$, (6) $1.5 \mathrm{~V}$, and (7) $2.0 \mathrm{~V}$ were gradually applied to graphene again as shown in the second light-green area within Fig. 3. Similar resistances of graphene were obtained from the first measurement denoted by the blue area in Fig. 3. Although, the variation of resistance as a function of $V_{W G}$ was observed, this result was not enough to clearly understand the effect of $V_{W G}$ on the accumulated carrier density variation on graphene. Thus, $V_{\mathrm{CNP}-\mathrm{BG}}$ from the resistance curves was represented as a function of $V_{B G}$ [Fig. 4] after each $V_{W G}$ at (1) (7) were applied to graphene, as shown in Fig. 3.

Figure 4(a) presents the resistance curves of graphene as a function of $\mathrm{V}_{\mathrm{BG}}$ after the application of $\mathrm{V}_{\mathrm{WG}}=(0) 0 \mathrm{~V}$, (1) $-0.6 \mathrm{~V}$, and (3) $0.7 \mathrm{~V} \sim$ (7) $2.0 \mathrm{~V}$. Compared with the neutral point of $\mathrm{V}_{\mathrm{CNP}-\mathrm{BG}}=$ $8.35 \mathrm{~V}$ [marked by the black dashed line of the black transport curve in Fig. 4(a)] under (0) $\mathrm{V}_{\mathrm{WG}}=0 \mathrm{~V}, \mathrm{~V}_{\mathrm{CNP}-\mathrm{BG}}$ was increased by approximately $10 \mathrm{~V}$ [the red transport curve in Fig. 4(a)] for (1) $-0.6 \mathrm{~V}$ and $\mathrm{V}_{\mathrm{CNP}-\mathrm{BG}}$ remained approximately $10 \mathrm{~V}$ during the application of $\mathrm{V}_{\mathrm{WG}}=(2) 0.7 \sim(5) 1.2 \mathrm{~V}$ [denoted by the dashed transport curves in Fig. 4(a)]. When $V_{\text {WG }}$ greater than (6) $1.5 \mathrm{~V}$ and (7) $2.0 \mathrm{~V}$ was applied [the blue and brown transport curves in Fig. 4(a)], $\mathrm{V}_{\mathrm{CNP}-\mathrm{BG}}$ decreased by approximately $3 \mathrm{~V}$.

As an estimate of the variation of the accumulated carrier density (n), Fig. 4(b) exhibits the relationship between $n$ and $V_{\text {WG. The }}$ accumulated carrier density was observed to be $n=5.09 \times 10^{11}$ and $10.65 \times 10^{11} \mathrm{~cm}^{-2}$ for $\mathrm{V}_{\mathrm{WG}}=(0) 0 \mathrm{~V}$ and (1) $-0.6 \mathrm{~V}$, respectively. As previously mentioned with regard to $\mathrm{V}_{\mathrm{CNP}-\mathrm{wG}}$ in Fig. 4(a), although $\mathrm{V}_{\mathrm{WG}}=(2) 0.7 \mathrm{~V} \sim$ (5) $1.2 \mathrm{~V}$ were applied, the carrier density was maintained between $n=10 \times 10^{11}$ and $n=13 \times 10^{11} \mathrm{~cm}^{-2}$, as marked by pink area in Fig. 4 (b). Meanwhile, $n \approx 2 \times 10^{11} \mathrm{~cm}^{-2}$ was measured for $\mathrm{V}_{\mathrm{WG}}=(6) 1.5 \mathrm{~V} \sim$ (7) $2.0 \mathrm{~V}$ as marked by blue area in Fig. 4(b). Moreover, similar behavior [red dots in Fig. 4(b)] was also observed in the second cycle with the application of $\mathrm{V}_{\mathrm{WG}}=(1)-0.6 \mathrm{~V}$, (6) $1.5 \mathrm{~V}$, and (7) $2.0 \mathrm{~V}$ after finishing the first cycle in its entirety. This indicates that although water-gating leads to changes in the doping of graphene when negative electric potential $\left(\mathrm{V}_{\mathrm{WG}}=-0.6 \mathrm{~V}\right)$ is applied, a critical

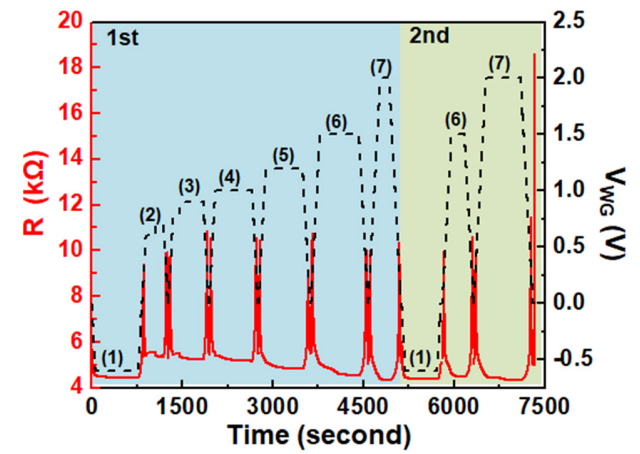

Figure 3. (Color online) Resistance variation of graphene as a function of time for different applied $\mathrm{V}_{W G}=(1)-0.6 \mathrm{~V}$, (2) $0.7 \mathrm{~V}$, (3) $0.9 \mathrm{~V}$, (4) $1.0 \mathrm{~V}$, (5) $1.2 \mathrm{~V}$, (6) $1.5 \mathrm{~V}$ and (7) $2.0 \mathrm{~V}$. The water-gating ranges from $V_{W G}=(1)-0.6 \mathrm{~V}$ to (7) $2.0 \mathrm{~V}$ were applied twice, with the first and second applications denoted by the blue and green areas, respectively.
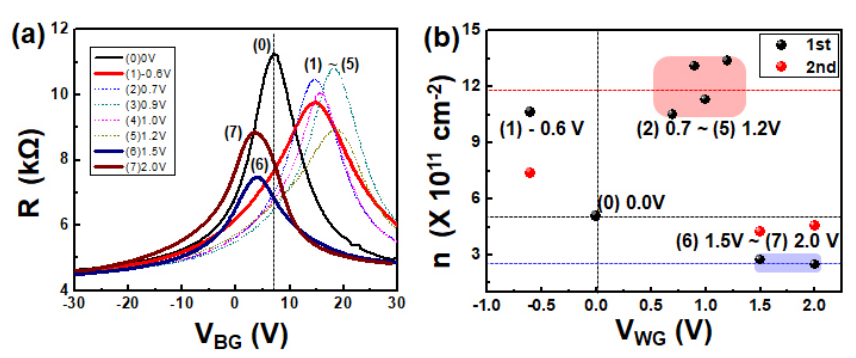

Figure 4. (Color online) (a) Resistance curves of graphene as a function of $V_{B G}$ after applied $V_{W G}$ from (1) $-0.6 \mathrm{~V}$ to (7) $2.0 \mathrm{~V}$. (b) Accumulated carrier density of graphene as a function of $\mathrm{V}_{\text {WG }}$ for (0) $0.0 \mathrm{~V}$, (1) $-0.6 \mathrm{~V}$, (2) $0.7 \mathrm{~V} \sim(5) 1.2 \mathrm{~V}$, and (6) $1.5 \mathrm{~V} \sim(7)$ $2.0 \mathrm{~V}$. Black and red dots indicate the $n$ for the first and second cycles of $V_{W G}$ application.

positive electric potential $\left(\mathrm{V}_{\mathrm{WG}} \geq 1.5 \mathrm{~V}\right)$ can be applied to return accumulated carrier density to its initial condition from the highly p-doped condition generated by negative electric potential.

\section{Conclusions}

In this work, carrier density accumulation was observed in response to DI-water gating. When a critical negative electric potential $\left(\mathrm{V}_{\mathrm{WG}}=-0.6 \mathrm{~V}\right)$ was applied via DI-water, the accumulated hole carrier density was observed. Furthermore, once the applied voltage exceeded a critical positive electric potential $\left(\mathrm{V}_{\mathrm{WG}} \geq 1.5 \mathrm{~V}\right)$ through DI-water, this accumulated carrier density could be restored to the initial carrier density condition. This result provides meaningful insight into the relationship between carrier accumulation and the DI-water gating method.

\section{Acknowledgements}

This work was supported by the research fund of Chungnam National University.

\section{References}

[1] K. S. Kim, Z. Yue, H. Jang, S. Y. Lee, J. M. Kim, K. S. Kim, J. H. Ahn, P. Kim, J. Y. Choi, and B. H. Hong, Nature 457, 706 (2009). 
[2] X. Li, W. Cai, J. An, S. Kim, J. Nah, D. Yang, R. Piner, A. Velamakanni, I. Jung, E. Tutuc, S. K. Banerjee, L. Colombo, and L. R. S. Ruoff, Science 324, 1312 (2009).

[3] S. Bae, H. Kim, Y. Lee, X. Xu, J. S. Park, Y. Zheng, J. Balakrishnan, T. Lei, H. R. Kim, and Y. I. Song, Nat. Nanotechnol. 5, 574 (2010).

[4] E. R. Goldsmith, J. G. Coroneus, V. R. Khalap, A. A. Kane, G. A. Weiss, and P. G. Collins, Science 315, 77 (2007).

[5] L. Liu, S. Ryu, M. R. Tomasik, E. Stolyarova, N. Jung, M. S. Hybertsen, M. L. Steigerwald, L. E. Brus, and G. W. Flynn, Nano Lett. 8, 1965 (2008).

[6] A. B. Kalser, C. Gómez-Navarro, R. S. Sundaram, M. Burghard, and K. Kern, Nano Lett. 9, 1787 (2009).
[7] S. Sorgenfrei, C. Chiu, R. L. Gonzalez, Y. J. Yu, P. Kim, C. Nucklls, and K. L. Shepard, Nature Nanotechnol. 6, 126 (2011).

[8] Y. Choi, J. Kang, D. Jariwala, M. S. Kang, T. J. Marks, M. C. Hersam, and J. H. Cho, Adv. Mater. 28, 3742 (2016).

[9] R. C. Ordonez, C. K. Hayashi, C. M. Torres, J. L. Melcher, N. Kamin, G. Severa, and D. Gamire, Sci. Rep. 7,1017 (2017).

[10] Y. J. Yu, Appl. Sci. Converg. Technol. 27, 35 (2018).

[11] Y. J. Yu, Appl. Sci. Converg. Technol. 28, 51 (2019).

[12] Y. J. Yu, J. Korean Phys. Soc. 74, 132 (2019).

[13] B. G. Sonomez, O. Ertop, and S. Mutlu, Sci. Rep. 7,12190 (2017).

[14] Y. J. Yu, Y. Zhao, S. Ryu, L. E. Brus, K. S. Kim, and P. Kim, Nano Lett. 9, 3430 (2009). 